\title{
Research Trends in Science and Mathematics Education in South Korea 2014-2018: A Cross-Disciplinary Analysis of Publications in Selected Local Journals
}

\author{
Wonyong Park | ORCID: 0000-0002-8911-5968 \\ Corresponding author, \\ Southampton Education School, University of Southampton, University \\ Road, Southampton, $\mathrm{SO} 17$ 1BJ, UK \\ w.park@soton.ac.uk

\section{Doy Kim} \\ Department of Educational Psychology, University of Wisconsin-Madison, \\ 1025 W. Johnson St., Madison, WI, 53706, USA \\ doy.kim@wisc.edu
}

\author{
Da Yeon Kang | ORCID: 0000-0001-6022-0652 \\ Corresponding author, \\ Seoul National University, 1, Gwanak-ro, Gwanak-gu, Seoul o8826, Republic \\ of Korea \\ dayeon.kang.9@gmail.com
}

Received: 27 November 2020 | Revised: 4 October 2021 |

Accepted: 11 October 2021

\begin{abstract}
Although science education and mathematics education share many characteristics as neighboring research disciplines, comparisons between the two research fields in the literature have rarely been made. In this study, we examine the two fields' similarities and differences in the local context of South Korea by analyzing 2,426 research articles published in 15 selected local journals from both fields. The analysis revealed interesting commonalities and divergences across the two fields, suggesting a high degree of similarity in the distribution of research topics across the two fields. Nevertheless,
\end{abstract}


some topics were more frequently studied in one field than the other. Based on the results, we suggest that understanding the ongoing research agendas and aims of adjacent disciplines such as mathematics education will be beneficial to the science education community by allowing self-reflection and facilitating interdisciplinary communication and collaboration. Several potential ways in which the two disciplines can cross-fertilize are discussed.

\section{Keywords}

research trend - comparative analysis - subject-based educational research - science education research - mathematics education research

\section{1 \\ Introduction}

Both science education research (SER) and mathematics education research (MER) are important subfields of educational research today. As neighboring academic research fields, the two share many characteristics. In terms of the curriculum, both subjects concern logic and process and are both relevant to human lives in the current highly technological modern society. The U.S. Science for All Americans acknowledge this by stating that achieving scientific literacy requires not only a sound understanding of science but also of mathematics (AAAS, 1989). The fact that many North American universities provide graduate programs in "science and mathematics education" jointly rather than separately also shows the proximity of the two fields in higher education and research today. As a more recent phenomenon, SER and M ER have been jointly addressed in a larger context referred to as Science Technology Engineering Mathematics (STEM) education, meaning the teaching of science, technology, engineering, and mathematics in an integrated manner (English, 2016).

Despite these resemblances, however, SER and MER are distinct research fields, having developed research questions and methods specific to the disciplinary contexts of each. One fundamental difference seems to come from the nature of their parent disciplines. Mathematics is essentially a theoretical discipline that studies the patterns and relationships among abstractions of nature, with little interest in how they correspond to physical objects in the real world (AAAS, 1989). Science, on the other hand, is an empirically based discipline that deals with the physical world. These differences are in line with a more general trend that the practice of subject-based educational research is largely influenced by the nature of the parent discipline (Singer et al., 2012). 
This means that, whereas SER and MER share some elements of their research paradigms by being sub-disciplines of educational research, it is likely that each of them has developed research methods and interests that are distinct from the other. Several studies have pointed to the potential benefits of comparing science and mathematics as school subjects (Bishop, 2008; Tobin \& Fraser, 1988).

In this article, our aim is to examine how SER and MER are similar and different in terms of research topics addressed, examining in particular the context of South Korea. For several decades, South Korea (hereafter referred to as Korea) has been one of the top countries in international science and mathematics assessment schemes such as PISA (OECD, 2018, 2019) and TIMSS (TIMSS and PIRLS International Study Center, 2015a, 2015b) and has had active research communities in both fields. Therefore, examining publications by Korean science education and math education researchers can offer domestic and international implications by identifying and comparing what Korean researchers regard as important issues and how they approach these issues. In particular, there are many local journals for communicating research findings on science and mathematics education in which more than 300 studies are communicated annually in each discipline. These non-English local journal publications, despite their significance in educational practice in the relevant region (Liu, 2017), are underrepresented in the literature primarily because of the language barrier. An analysis of these articles can thus provide helpful information for understanding the research interests and trends in Korean science and mathematics education communities. In addition, considering that most existing studies of research trends in SER and MER (Lin et al., 2014, 2018) have only addressed one discipline but not both, a comparison of the two can offer new perspectives that may not be seen within their respective contexts. A comparative study of SER and MER would provide initial information on the similarities and differences in the researchers' interests and approaches, which will enrich our understanding of each discipline's research trends in recent years. Moreover, considering that there has been a growing interest in the interdisciplinary collaboration between SER and MER in line with integrated STEM and Science Technology Engineering Arts and Mathematics (STEAM) initiatives (English, 2016; Park, Wu \& Erduran, 2020), a comparative meta-analysis of research will also be useful in navigating the future direction in cross-subject integrations and collaborations.

The research questions that guided our analysis were:

1. What research topics are found in Korean SER and MER journal articles?

2. How do the topics found in Korean SER and MER journal articles compare between the two fields? 


\subsection{Plurality of Educational Research across Disciplines and across Countries}

From the broader scope of educational research, SER and MER can be viewed as examples of educational research with specific subjects of focus. They both deal with issues, problems, pedagogies, and challenges that are specific to each discipline rather than those applicable across all school subjects. Despite its short history relative to subject-general educational research, subject-based educational research has gained increasing significance (Dolan et al., 2018; Singer et al., 2012) as the school curriculum has been divided into specialized subjects. Specifically pointing to SER and MER, Ernest (1997) contended that the two fields "for too long [had] had a parallel but separate existence" (p. 82), sharing a number of concerns such as adopting constructivism as a theoretical foundation, the application of humanistic theories such as hermeneutics and postmodernism, history and philosophy of the discipline, problem-solving and inquiry processes, and gender and race imbalances in the subject.

On the fundamental level, the issue of similarity and difference relates to how we understand the nature of each research field. Systematic reflections on the nature of the discipline began among MER scholars in 1994 when the International Commission on Mathematical Instruction (ICMI) Study Conference "What is research in mathematics education, and what are the results?" was held in Washington, DC, United States. This was where mathematics educators asked themselves important questions about the nature of MER as an academic discipline:

- What is the specific object of study in mathematics education?

- What are the aims of research in mathematics education?

- What are the specific research questions in mathematics education?

- What are the results of research in mathematics education?

- What criteria should be used to evaluate the results of research in mathematics education? (Sierpinska \& Kilpatrick, 1997, pp. 4-8)

Similarly, in science education, Fensham (2003) provided several key criteria that define the nature of an academic discipline: academic recognition, research journals, professional associations, research conferences, research centers, and research training (structural criteria); scientific knowledge, asking questions, conceptual and theoretical development, research methodologies, progression, model publications, and seminal publications (intra-research criteria); and implications for practice (outcome criteria). While the two sets of categories proposed by ICMI and Fensham both point to similar aspects of what characterizes a discipline, again, it is important to remember that the 
answers (or properties) corresponding to each of these are not the same across disciplines. Philosophers, historians, and educators of science have demonstrated over decades that researchers in different fields work on different problems based on different methods and epistemic aims (Erduran \& Dagher, 2014; Hacking, 1996; Kuhn, 2012; Park \& Song, 2019). This suggests that identifying the commonalities and divergences between SER and MER can help understand the nature of each field and also explore the potential areas of crossfertilization and interdisciplinary collaboration.

In addition to the variations stemming from disciplinary differences, it should be noted that the trends of educational research may also vary across geographical locations. This is no surprise to educational researchers, given that the research interests, available data sources, and research-practice connections are all dependent upon the local contexts of policy and curriculum. Korea, an East Asian country, has its own system and culture of science and mathematics education that has been shown to have a disparity between students' high achievement in high-stakes international assessment schemes and low engagement (Song, 2013). Korean classrooms have been shaped within the broader cultural context of the Confucian tradition, which has remained deeply entrenched in society up to the present and has produced a highly competitive classroom culture characterized by "education fever" (Seth, 2002) and "testocracy" (Kwon, Lee, \& Shin, 2017). Another regional factor that is common across the East Asian countries is that they tend to have highly centralized education systems (Morris \& Marsh, 1992), where a national curriculum specifies the subject matter knowledge, instructional approaches, and assessment criteria in great detail. This suggests that the research trends are likely to be responsive to, and bound by, the curriculum policy at each moment. In other words, a large number of research projects tend to deal with local science and mathematics education policy issues rather than generic research themes. Such interdependence of SER and MER on regional contexts clearly calls for scholarly attention to local trends for each discipline.

\subsection{Research in Science and Mathematics Education in Korea}

2.2.1 Science Education Research Publication in Korea

Every year, the largest number of research papers are communicated via the Journal of the Korean Association for Science Education (JKASE), the flagship journal of the Korean Association for Science Education (KASE). An average of 82.4 articles were published annually during 2009-2018 in JKASE. The Journal of Science Education (JSE) is another journal that covers a wide range of topics in SER and is published by the Science Education Research Institute at Kyungpook National University. The practice-oriented research journal School Science Journal (sSJ) has been publishing research papers since 2007. 
The Journal of Korean Elementary Science Education (JKESE) covers a range of research topics focusing on science education at the elementary level. While the scopes of these journals vary by their aims and intended readers, they are similar in that the published studies usually address general issues in SER rather than issues specific to a particular sub-discipline of science (e.g., chemistry, biology, and earth science).

Two education journals, the Journal of the Korean Society of Earth Science Education (JKSESE) and Biology Education (BE) are published by local academic societies for earth science education and biology education, respectively. Most of the studies published in these two journals are required to address issues related to the disciplinary contexts of earth science and biology. Similar discipline-specific journals are New Physics: Sae Mulli (NPSM), the Journal of the Korean Chemical Society (JKCS), and the Journal of the Korean Earth Science Society (JKESS), published by the Korean Physical Society, the Korean Chemical Society, and the Korean Earth Science Society, respectively. NPSM, JKCS, and JKESS publish both scientific research on each discipline and discipline-based educational research, with around $15^{-30} \%$ of their published articles being education research on the respective disciplines. These discipline-specific journals have a longer history than the journals with a general science education focus due to the earlier establishment of their affiliated scientific societies compared to science education societies in Korea (Song et al., 2016). The divide between discipline-general and discipline-specific SER in Korea is in fact a microcosm of the international science education community, where journals such as the Journal of Research in Science Teaching and the International Journal of Science Education publish more articles that address discipline-general issues in SER than subject-focused journals such as Physical Review Physics Education Research, the Journal of Chemical Education, the Journal of Biological Education, and the Journal of Geoscience Education.

Song et al's (2016) analysis of the articles published in JKASE and JKESE revealed that the most common research topics included (1) science teaching practice; (2) policy, curriculum, evaluation, and assessment; and (3) science learning related to inquiry and practical work. They also found that quantitative studies outnumbered qualitative and mixed-methods studies in these two journals. While their report provided valuable insights about SER trends in Korea, it indicates a need for further, more comprehensive trend analysis with a wider selection of research journals that include discipline-specific SER journals in Korea. Other authors have studied the trends in SER with more specialized topical interests. These include research trend analyses on integrated STEM education (Kwon \& Ahn, 2012), science learning progressions (Maeng, Seong, \& Jang, 2013), science writing (Shin \& Choi, 2014), science learning (Kim et al., 2015), and assessment of science learning (Chung \& Shin, 2016). 


\subsubsection{Mathematics Education Research Publication in Korea}

The majority of articles that address various issues regarding teaching and learning mathematics in the school context are published via School Mathematics $(s M)$, which is the journal for the Korean Society of Educational Studies in Mathematics (KSESM). SM has published the largest number of MER papers, with an average of 39.2 articles per year for the past 5 years. The Journal of the Korean School Mathematics (JKSM) is another major MER journal, published by the Korean School Mathematics Society (KSMs). Research papers specifically concerned with elementary school mathematics education are communicated in the Journal of Elementary Mathematics Education in Korea (JEMEK) and Education of Primary School Mathematics (EPSM), published by the Korean Society of Elementary Mathematics Education (KSEME) and the Korean Society of Mathematical Education (KSME), respectively. The Journal of Educational Research in Mathematics (JERM) is another prolific journal from KSESM that has published an average of 36.4 original articles yearly. JERM is primarily committed to the communication of theoretical research or research with theoretical implications for MER. The MathematicalEducation (TME) and Communications of Mathematical Education (CME) cover a wide range of topics on all aspects of mathematics education, both published by KSME. TME is the oldest MER journal in Korea, while $C M E$ is the third most prolific MER journal, publishing an average of 30.2 articles per year. Unlike in the case of SER, there are currently no journals that cover both professional mathematics research and MER.

There have been a handful of research trend analyses within MER published in the past decade. Among them, Kim and Pang (2017) reviewed articles on elementary school mathematics to investigate various trends from 2003 to 2013. The results showed that the most studied topics included (1) learners' cognitive and affective characteristics, (2) curriculum and textbooks, and (3) instruction and pedagogy. Park and Kim's (2011) analysis of articles published in TME and JERM from 2005 to 2009 showed that the most common research topics were (1) mathematical concepts, (2) problem solving, (3) teaching and learning, and (4) curriculum and education systems.

\subsubsection{Cross-Field Communication}

Some evidence suggests that Korea is not an exception regarding a lack of communication between SER and MER. Although no well-defined measure of cross-field communication currently exists, the journal citation information from the Korean Citation Index (KCI) website suggests that it is highly likely. According to the citation information of the 1,497 articles published in JKASE since 20O2, there is no MER journal in the list of top 20 journals that JKASE 
articles cite or the top 20 that cite JKASE. For School Mathematics, JKASE was the 17th most often cited journal (17 of 2,762 citations) and the 17th that it most often cites (26 of 3,861 citations), while no other science education journals were listed in the 20 most citing or cited journals. These data provide evidence that the communication between SER and MER in Korea is currently rare and limited.

\section{3}

\section{Methods}

\subsection{Common Framework for Coding}

Although research trends in SER and MER in Korea have been analyzed separately by many researchers, the information these analyses offer for understanding the commonalities and differences between the two fields has been limited. This is primarily because none of these trend analyses were done with a comparison of SER and MER in mind, and these studies used article classification systems based only on the field being studied. In the current study, to ensure a fair and rich comparison between the research trends in the two different fields, it was necessary to develop a classification system that could be used to code articles from both fields. With this aim in mind, we consulted the research strand classifications widely used by major conferences and journals in SER and MER to categorize their submissions. These included the European Science Education Research Association (ESERA; ESERA, 2019) and the National Association for Research in Science Teaching (NARST; NARST, 2018) for SER, and the 2010 Mathematics Subject Classification (2010MSC; AMS, 2010) and zDM Subject Classification Scheme (zDM, n.d.) for MER. In developing the common research strands, we were careful to define the strands in ways that were broad enough to enable comparing general trends but had detailed enough categories to capture fine-grained differences between the two. Our initial coding scheme had a coding category for school level (elementary, secondary, and tertiary, and teacher education), but it was not included in the final analysis since a fair number of articles did not fit into only one of these codes (e.g., teacher professional development studies with both university-based and school-based components). Thus, we finalized categories with a focus on the research topics to capture the general research trends of SER and MER. Of the nine strands, three strands (C, L, T; see Table 1) were further divided into numbered sub-strands for a closer and more nuanced examination of the trends. These initial strands were refined and regrouped multiple times as the analysis progressed to better represent the diverse research topics in both fields. Table 1 shows the final list of strands with descriptions and illustrative examples. 
TABLE 1 Cross-subject research strands for SER and MER (ordered by the frequency in SER)

\section{L: Learning and instruction}

L1 Affect, emotion, attitude, and character education

L2 Argumentation and proof

Understanding, supporting, and promoting use of evidence and argumentation, justification, and proof.

L3 Discourse and classroom interaction

Supporting the development of critical thinking. Discourse analysis.

Talking and writing science in the classroom. Meaning-making in science classrooms.

L4 Cognitive aspects

Analogy and metaphor, modeling, thinking process, and problem solving

L5 Conceptual understanding and conceptual change

Conceptual understanding, alternative conception, and conceptual change

L6 Practical work and inquiry

Student-led projects, practical work, laboratory science and mathematics, and scientific practice

L7 Representation

Visualization, graphical and textual representation, and semiotics

L8 Technology and digital resources

Computers, interactive multimedia, video, and other technologies

L9 Instructional strategies

Design of teaching interventions, teaching-learning sequences, and instructional tasks

\section{C: Curriculum, policy, and assessment}

C1 Curriculum development and implementation

Design, development, implementation, and evaluation of curricula at diverse levels

$\mathrm{C} 2$ Curriculum resources and textbooks

Design and analysis of textbooks, teachers' guides, and other instructional materials

C3 Educational systems and policies

The construction, interpretation, and implementation of science

education policies and reforms at the local, regional, national, and international levels

$\mathrm{C}_{4}$ Evaluation and assessment

Development, validation and use of high-stakes, external, large-scale, formative, and summative assessments 
TABLE 1 Cross-subject research strands for SER and MER (cont.)

T: $\quad$ Teaching and teacher education

T1 Professional development

Design, implementation, and evaluation of professional development programs for pre- and in-service teachers

T2 Teacher knowledge, beliefs, and identity Pedagogical content knowledge, beliefs, and identity related to teaching and the disciplines

T3 Teacher practice and teaching process Instructional design and practices, improvement of teaching, and teaching strategies and processes

S: STEM/STEAM education

Science, technology, engineering, (arts), and mathematics education; cross-subject integration; and interdisciplinary approaches to teaching

D: Diversity and equity

Equity and diversity issues: sociocultural, multicultural, bilingual, racial/ethnic, and gender equity studies.

G: Generic and review

Review and meta-analysis of research literature in SER and MER and specific subtopics in the disciplines

M: Methodological issues

Meta-analysis of research methods and approaches, proposal of new method

$\mathrm{N}$ : Nature, history, philosophy, and sociology of science and mathematics

Historical, philosophical, and social issues of science and mathematics as related to teaching

I: Informal and out-of-school education Learning and teaching in museums, outdoor settings, community programs, communications media, and after-school programs.

\subsection{Selection of Publications}

For the trend analysis, we used the articles published in journals that were indexed in KCI during the entire 5 years included in the analysis (2014-2018, beginning and ending years inclusive). Similar to the Science Citation Index (SCI) and Social Science Citation Index (SSCI), which cover academic journals with international impact, $\mathrm{KCI}$ is a database of Korean academic journals provided by the National Research Foundation of Korea. Since the journals listed in KCI are considered significant among researchers, an analysis of articles in these journals was reasonably expected to represent the research trends in Korea. Articles published in 15 KCI-listed journals (8 SE R, 7 MER) were exported 
from the database with their title and keyword information from the KCI website (http://www.kci.go.kr/). Besides original research articles, academic journals often publish alternative forms of manuscripts under titles such as "editorial," "comment," "forum," and "book review." However, the selected journals either did not publish these alternative manuscript types, or they were not indexed in the database. As a result, the retrieved lists of articles consisted entirely of original research articles. These lists included review articles, which we included in the analysis because they also represent the general interests of the community in the research topics being reviewed. Since the data analysis was conducted in 2019, and all the 14 current KCI journals have been indexed since at least 2014, we included articles published during the immediate past 5 years (2014 to 2018, inclusive) to explore the latest research trends of SER and MER fields with the available data at the moment. The number of articles published in these journals during this period is indicated in Table 2, all of which were subject to analysis.

\subsection{Coding and Reliability}

Given that SER and MER are two related but distinct fields, maintaining consistency across the two disciplines was the main concern for this comparative study. To accomplish this, three coders (two from SER, one from MER) conducted multiple rounds of coding to establish inter-coder reliability across the two fields. As a preliminary stage, 100 randomly selected articles (5o from SER and 50 from MER) were coded independently by the three coders, and the results were discussed to determine detailed criteria for inclusion in each strand. This discussion also involved adding, removing, and revising the analytical framework to better represent the research trends while minimizing overlaps among strands. In the main analysis, all SER articles were coded by one coder (science education researcher), all MER articles by another coder (mathematics education researcher), and all 2,426 articles were then independently coded by the third coder (science education researcher, first author). As a result, each article was coded by two different coders.

Each coder read the title and keywords of the articles and judged which of the strands in the framework could best represent the content of each article, based on the assumption that the title and keywords reflect the nature and core content of the article to a reasonable extent. Most articles could be coded into one strand through this process, but some articles with rhetorical, generic, or comprehensive titles required examination of their abstracts and sometimes main texts to clearly understand the focus of the study. If an article could be coded into more than one strand, the coder decided the principal strand based on the content of the article. In so doing, the first and second coders 
TABLE 2 Selected SER and MER journals and numbers of articles

\begin{tabular}{|c|c|c|c|}
\hline Discipline & Journal name & $\begin{array}{l}\text { Number of articles } \\
2014^{-2018}\end{array}$ & Total \\
\hline \multirow[t]{10}{*}{ SER } & Journal of the Korean Association for & 395 & \\
\hline & Science Education (JKASE) & & 1,394 \\
\hline & Journal of Science Education (JSE) & $15^{1}$ & \\
\hline & School Science Journal (ssJ) & 147 & \\
\hline & Journal of Korean Elementary Science & 206 & \\
\hline & Education $(J K E S E)$ & & \\
\hline & New Physics: Sae Mulli (NPSM)* & 147 & \\
\hline & $\begin{array}{l}\text { Journal of the Korean Chemical Society } \\
(J K C S)^{*}\end{array}$ & 69 & \\
\hline & Biology Education $($ BE) & 234 & \\
\hline & $\begin{array}{l}\text { The Journal of the Korean Earth Science } \\
\text { Society (JKESS)* }\end{array}$ & 45 & \\
\hline \multirow[t]{8}{*}{ MER } & The Mathematical Education (TME) & 124 & 1,032 \\
\hline & $\begin{array}{l}\text { Communications of Mathematical } \\
\text { Education }(C M E)\end{array}$ & $15^{1}$ & \\
\hline & $\begin{array}{l}\text { Journal of Educational Research in } \\
\text { Mathematics (JERM) }\end{array}$ & 182 & \\
\hline & $\begin{array}{l}\text { Education of Primary School } \\
\text { Mathematics (EPSM) }\end{array}$ & 100 & \\
\hline & School Mathematics (sM) & 196 & \\
\hline & Journal of Elementary Mathematics & 148 & \\
\hline & Education in Korea $(J E M E K)$ & & \\
\hline & $\begin{array}{l}\text { Journal of the Korean School } \\
\text { Mathematics (JKSM) }\end{array}$ & 131 & \\
\hline
\end{tabular}

* In the three mixed journals (NPSM, JKCS, and JKESS), only educational research articles were counted and used for analysis.

focused on consistency within each field, and the third coder paid particular attention to the coding criteria being applied consistently across the two fields. An initial agreement of $78.28 \%$ for SER and $77.62 \%$ for MER was reached. Most of the disagreements arose in articles that could potentially belong to multiple strands in the framework. To resolve these discrepancies, we met to discuss the disagreements and decide further criteria for coding, fine-tuned the categories to minimize overlap, and recoded the entire articles based on the 
new criteria. This procedure was repeated until 100\% agreement on coding was reached. In the meantime, each coder also wrote memos on any notable quantitative and qualitative aspects of the data, whether common or distinct between SER and MER. For example, when we noticed that one strand took up significantly different proportions in SER and MER (e.g., Strand I and Strand S), we looked into the categories within the strand to further consider the possible reasons for such a difference. Conversely, for those strands that took up similar proportions in SER and MER, we were keen to investigate any qualitative differences between the two fields. For example, although textbook research was found to be popular in both SER and MER, after looking into the articles' content, we concluded that there were different foci in textbook studies in SER (with diverse foci such as inquiry activities and gender stereotypes) and MER (mostly focused on mathematical content). As such, analytical memos provided nuances that could not be captured through framework-based coding and were discussed in the analysis meetings.

\section{$4 \quad$ Results}

We analyzed 2,426 papers published in SER and MER during the years 2014-2018 based on the developed research strand framework. As indicated in Table 3, the three strands most frequently addressed were L (learning and instruction), $\mathrm{C}$ (curriculum, policy, and assessment), and $\mathrm{T}$ (teaching and teacher education). These three strands accounted for $85.3 \%$ of SER and MER papers during the 5 years ( $\mathrm{L}, 42.8 \% ; \mathrm{C}, 26.1 \%$; and $\mathrm{T}, 16.4 \%)$. The rest (14.7\%) of the articles belonged to Strands S (STEM/STEAM education), N (nature, history, philosophy, and sociology of science and mathematics), I (informal and out-of-school education), D (diversity and equity), G (generic and review), and M (methodological issues). Four papers in the MER journals were concerned with applied mathematics or the history of mathematics without any link to education, and we indicated these as N/A.

The distribution of research articles in SER and MER across strands was generally very similar, as seen in Figure 1, with research strands L, C, and T being the three main topics in both the SER and MER fields. These three strands accounted for $83.1 \%$ of SER and $88.2 \%$ of MER articles. Among the three, Strand L ( $43.8 \%$ in SER, $41.8 \%$ in MER) was the most dominant in both research fields, followed by Strands C (23.8\% in SER, $29.0 \%$ in MER) and T $(15.5 \%$ in SER, $17.5 \%$ in MER). Such a high degree of similarity is both interesting and surprising, given that the two fields have developed mostly independently in Korea, and cross-field interactions are not very evident, as discussed earlier. 


\begin{tabular}{|c|c|c|c|c|}
\hline Strand & Sub-strand & SER & MER & Total \\
\hline \multirow[t]{9}{*}{$\begin{array}{l}\text { Learning and } \\
\text { instruction }\end{array}$} & $\begin{array}{l}\text { Affect, emotion, attitude, and } \\
\text { character education }\end{array}$ & $8 \%(112)$ & $5 \cdot 5 \%(57)$ & $7 \%(169)$ \\
\hline & Argumentation and proof & $2.1 \%(29)$ & $1.7 \%(18)$ & $1.9 \%(47)$ \\
\hline & $\begin{array}{l}\text { Discourse and classroom } \\
\text { interaction }\end{array}$ & $3.9 \%(55)$ & $2 \%(21)$ & $3.1 \%(76)$ \\
\hline & Cognitive aspects & $6.7 \%(93)$ & $9.9 \%(102)$ & $8 \%(195)$ \\
\hline & $\begin{array}{l}\text { Conceptual understanding } \\
\text { and conceptual change }\end{array}$ & $6.1 \%(85)$ & $9 \cdot 3 \%(96)$ & $7 \cdot 5 \%(181)$ \\
\hline & Practical work and inquiry & $5 \cdot 3 \%(74)$ & $1.7 \%(18)$ & $3.8 \%(92)$ \\
\hline & Representation & $2.2 \%(30)$ & $2.1 \%(22)$ & $2.1 \%\left(5^{2}\right)$ \\
\hline & $\begin{array}{l}\text { Technology and digital } \\
\text { resources }\end{array}$ & $5 \cdot 3 \%(74)$ & $3.4 \%(35)$ & $4.5 \%(109)$ \\
\hline & Instructional strategies & $4.2 \%(59)$ & $6 \%(62)$ & $5 \%(121)$ \\
\hline \multirow{4}{*}{$\begin{array}{l}\text { Curriculum, } \\
\text { policy and } \\
\text { assessment }\end{array}$} & $\begin{array}{l}\text { Curriculum development and } \\
\text { implementation }\end{array}$ & $6.5 \%(90)$ & $5 \cdot 7 \%(59)$ & $6.1 \%(149)$ \\
\hline & $\begin{array}{l}\text { Curriculum resources and } \\
\text { textbooks }\end{array}$ & $11.3 \%(157)$ & $15.8 \%(163)$ & $13.2 \%(320)$ \\
\hline & $\begin{array}{l}\text { Educational systems and } \\
\text { policies }\end{array}$ & $2.2 \%(31)$ & $1.7 \%(18)$ & $2 \%(49)$ \\
\hline & Evaluation and assessment & $3 \cdot 9 \%(54)$ & $5 \cdot 7 \%(59)$ & $4 \cdot 7 \%(113)$ \\
\hline \multirow{3}{*}{$\begin{array}{l}\text { Teaching } \\
\text { and teacher } \\
\text { education }\end{array}$} & Professional development & $2.3 \%(32)$ & $4.2 \%(43)$ & $3.1 \%(75)$ \\
\hline & $\begin{array}{l}\text { Teacher knowledge, beliefs, } \\
\text { identity }\end{array}$ & $8.6 \%(120)$ & $9.2 \%(95)$ & $8.9 \%(215)$ \\
\hline & $\begin{array}{l}\text { Teacher practice and teaching } \\
\text { process }\end{array}$ & $4.6 \%(64)$ & $4.2 \%(43)$ & $4.4 \%(107)$ \\
\hline \multicolumn{2}{|c|}{ STEM/STEAM education } & $6.9 \%(96)$ & $2.8 \%(29)$ & $5.2 \%(125)$ \\
\hline \multicolumn{2}{|c|}{$\begin{array}{l}\text { Nature, history, philosophy, and sociology } \\
\text { of science and mathematics }\end{array}$} & $3 \cdot 3 \%(46)$ & $3.9 \%(40)$ & $3 \cdot 5 \%(86)$ \\
\hline \multicolumn{2}{|c|}{ Informal and out-of-school education } & $3.2 \%(45)$ & $0.1 \%(1)$ & $1.9 \%(46)$ \\
\hline \multicolumn{2}{|c|}{ Diversity and equity } & $1.5 \%(21)$ & $2.4 \%(25)$ & $1.9 \%(46)$ \\
\hline \multicolumn{2}{|c|}{ Generic and review } & $1.6 \%(22)$ & $1.7 \%(18)$ & $1.6 \%(40)$ \\
\hline \multicolumn{2}{|c|}{ Methodological issues } & $0.4 \%(5)$ & $0.4 \%(4)$ & $0.4 \%(9)$ \\
\hline \multicolumn{2}{|c|}{$\mathrm{N} / \mathrm{A}$} & ०\% (o) & $0.4 \%(4)$ & $0.2 \%(4)$ \\
\hline \multicolumn{2}{|l|}{ Total $^{\mathrm{a}}$} & $100 \%(1394)$ & $100 \%(1032)$ & $100 \%(2426)$ \\
\hline
\end{tabular}

a Note: Percentages in tables and figures may not total 100 due to rounding 
The minor research strands, however, began to show more differences in SER and MER publications. The strands showed different proportions in each field: Strands S (6.9\%), N (3.3\%), I (3.2\%), G (1.6\%), D (1.5\%), and M (0.4\%) in SER, and Strands N (3.9\%), S (2.8\%), D (2.4\%), G (1.7\%), M (o.4\%), and I $(0.2 \%)$ in MER. A comparison of the percentages of each strand in SER and MER in Figure 1 shows that are noticeable differences in strands I and S. Notably, Strand I appeared about 16 times more frequently in SER $(3.2 \%)$ than in MER (0.2\%). Also, Strand S research was not conducted in MER $(2.8 \%)$ as much as it was in SER $(6.9 \%)$. In the following, we describe the similarities and differences between SER and MER within each strand. Despite the overarching similarities across most strands, we identified several notable quantitative differences between sub-strands, as well as some qualitative features within a sub-strand.

\subsection{Learning and Instruction}

Strand L was the most frequently published category for both SER and MER; however, the distribution patterns within the strand were different in the two fields. Figure 2 shows that there are four categories, L1, L3, L6, and L8, that are significantly more frequently (>1.5 times) published in SER. L6, for example, was more frequent in SER by about three times. This suggests that science education researchers put more research emphasis on the processes of inquiry than mathematics education researchers do. One interesting contrast in L6 was that many MER studies focused on a specific stage in the mathematical inquiry

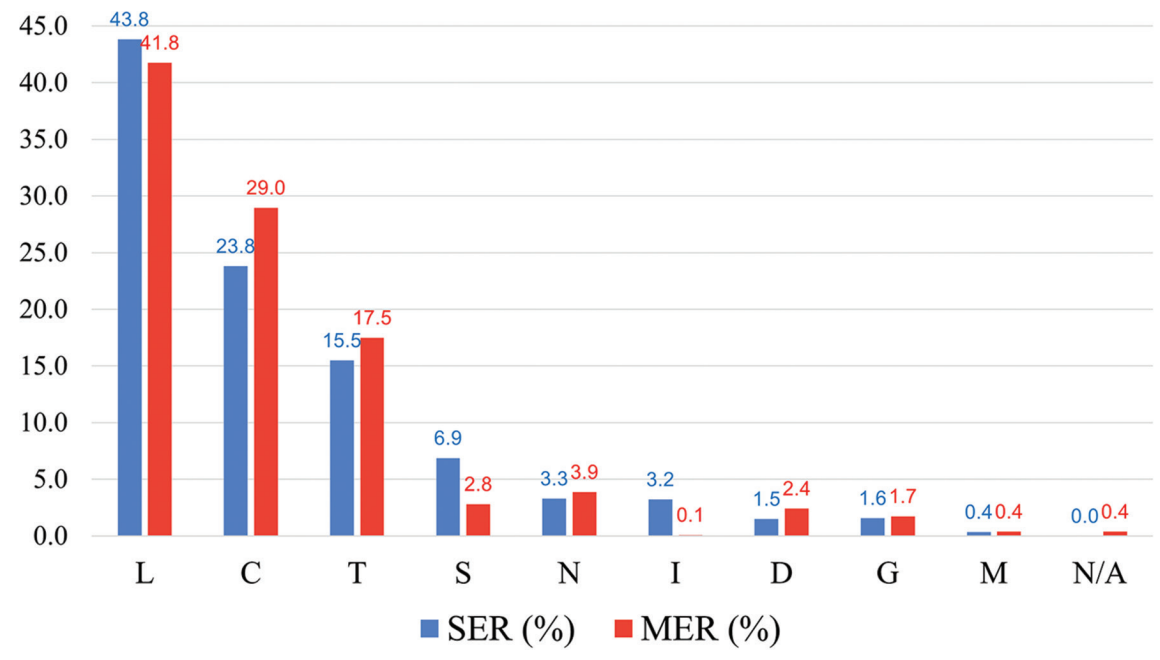

FIGURE 1 Overall distribution of SER and MER articles in Korean local journals (2014-2018) 
(e.g., posing a problem, solving a problem, measurement, or estimation), while most SER studies involved more than two of these stages in a single research design where scientific inquiry processes are generally taken as a whole rather than divided into smaller steps. On the other hand, the proportion of articles in $\mathrm{L}_{4}$ and L5 were significantly higher in MER. This could mean that, whereas in SER these research topics have been experiencing a steady decrease in issues such as conceptual understanding, conceptual change, and cognitive processes since the early 2000 (Lin, Lin, Potvin, \& Tsai, 2018), mathematics education researchers still have a sustained interest in these topics.

The proportions of L2 and L7 were similar between SER and MER but relatively small compared to those of other sub-strands. In terms of L2, most MER studies on argumentation understandably concerned students' proof activities in geometry. In SER, argumentation was discussed in relation to a diverse range of contexts, including scientific inquiry activities, practical work, and socioscientific issues. Another notable difference was that about half of SER argumentation studies were based on argumentation activities in groups, whereas most MER argumentation studies looked into the argumentation processes of individual students. In MER, the focus was on a formal process of proof in a particular content area (e.g., geometry, algebra, and number theory), whereas in SER, studies were focused on the structure of claims, evidence, and reasoning in student conversations. Despite these qualitative differences, there were a small number of exceptions. For example, one study in MER investigated middle school students' argumentation patterns during a problem-solving activity in geometry, which was similar to SER studies in terms of its focus on the social aspects of argumentation.

\subsection{Curriculum, Policy, and Assessment}

Strand C was the second most popular research strand in both fields. Figure 3 shows how the articles were distributed across the four sub-strands of this strand, showing that the design and analysis of textbooks and instructional materials gained the greatest interest among both science education and mathematics education researchers. This trend was more apparent in MER (15.8\%) than in SER (10.0\%). Such a high interest in textbooks can be explained in relation to the national context for textbooks, where the national curriculum, classroom practice, and college entrance examinations have been tightly coupled (Lew, 2016). When examined more closely, however, there were also notable differences in how science education and mathematics education researchers approached textbooks. MER studies on textbooks mostly focused on the way each textbook described a specific mathematical concept (e.g., 


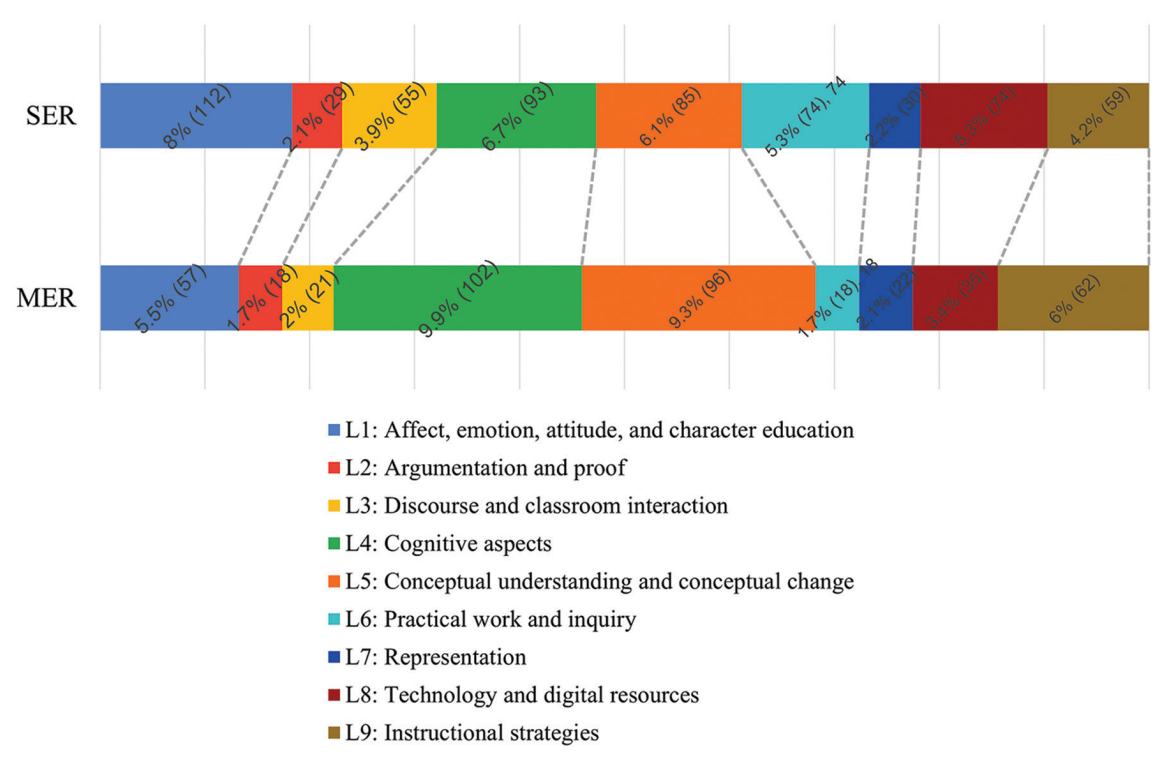

FIGURE 2 Distribution of SER and MER articles on learning and instruction

fractions, speed, multiplication, and congruence), whereas science education researchers tended to analyze textbooks from a range of different educational perspectives (e.g., types of inquiry activities, science writing tasks, gender stereotypes in textbooks, and use of scientific terms) rather than conceptual descriptions. Strand $\mathrm{C}_{4}$ accounted for relatively small proportions in both SER (3.8\%) and MER (5.7\%). Strand $\mathrm{C}_{3}$ drew the least attention, accounting for $3.8 \%$ in SER and $1.6 \%$ in MER. Given that $\mathrm{C}_{3}$ covers macroscopic analysis and interpretation of educational systems and policies, the relative lack of this category suggests that Korean SER and MER researchers are generally drawn more to classroom-level issues than the system issues that surround science and mathematics education practices. When it comes to $\mathrm{C}_{2}, 59$ of the 158 articles $(37.3 \%)$ coded as this strand came from School Science Journal, which is authored and read by both science teachers and researchers. A significant portion of articles in this journal were devoted to the proposal and application of new experimental apparatuses, inquiry activities, and specific teaching methods that would interest practitioners as well as researchers.

\subsection{Teaching and Teacher Education}

Strand T delivered studies that focused on pre- and in-service teachers. As illustrated in Figure 4, Korean researchers in SER and MER have had a substantial interest in issues related to teacher knowledge, beliefs, and identity $(8.6 \%$ 


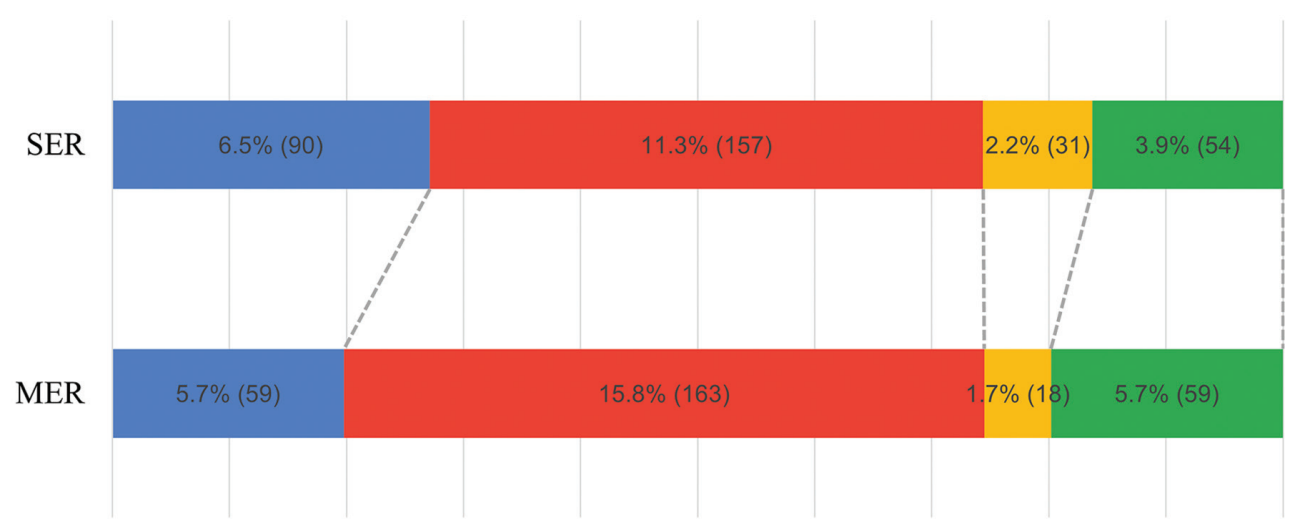

- C1: Curriculum development and implementation ${ }^{\mathrm{C}} \mathrm{C}$ : Curriculum resources and textbooks

-C3: Educational systems and policies

- C4: Evaluation and assessment

FIGURE 3 Distribution of SER and MER articles on curriculum, policy, and assessment

SER

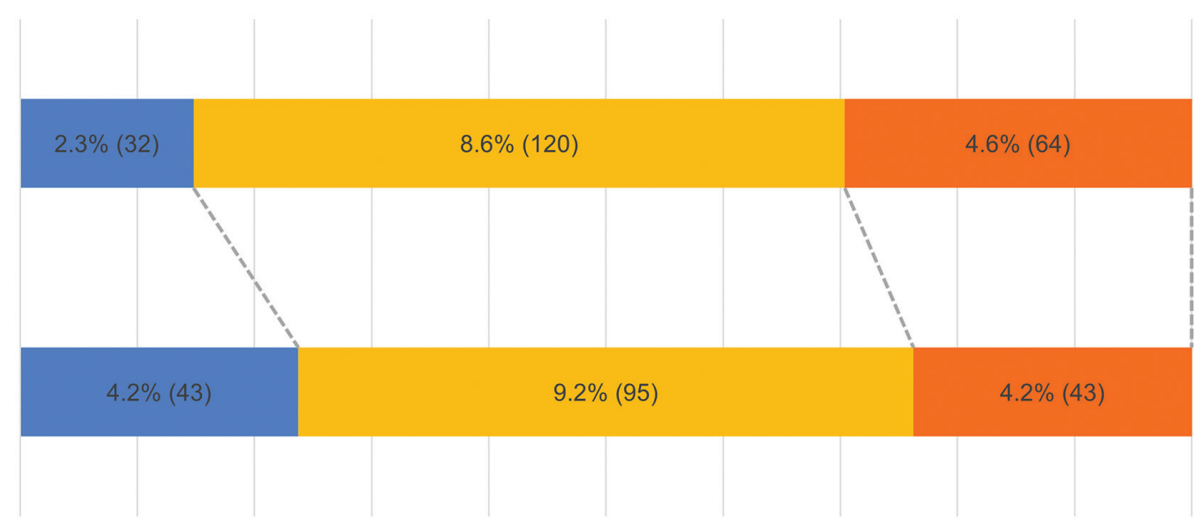

- T1: Professional development

T2: Teacher knowledge, beliefs, identity

- T3: Teacher practice and teaching process

FIGURE 4 Distribution of SER and MER articles on teaching and teacher education

and $9.2 \%$, respectively). More than half of the articles in this strand addressed teachers' pedagogical content knowledge, beliefs, and identities related to teaching science and mathematics. The rest of the articles were coded as substrands $\mathrm{T}_{1}(2.3 \%$ in SER and $4.2 \%$ in MER $)$ and $\mathrm{T}_{3}$ (4.6\% in SER and $4.2 \%$ in MER). This can be interpreted as mathematics education researchers having a relatively stronger interest in the design and implementation of professional development programs for pre- and in-service teachers. 


\subsection{Informal Education and STEM/STEAM Education}

Two of the strands were noteworthy in the sharp contrast they showed between SER and MER. In strands I and S, SER articles outnumbered MER articles to a great degree. The left side of Figure 5 indicates that studies on education in museums, outdoor settings, and after-school programs were conducted approximately 16 times more in SER than in MER. This can be interpreted as researchers in the SER field having more visible interest in teaching and learning in these places outside of school. The governmental policy promoting the foundation of science museums enacted by the Korean Ministry of Science and ICT in the 1980s (Jeon, 2013) has resulted in continuous attention and effort from science education researchers. Also, both international and domestic literature has indicated that science education research engaging citizens in science programs using community resources has been gaining increasing significance (Kim, 2018; Riesch \& Potter, 2014). In MER, however, there was only one article, which provided a conceptual reflection on a mathematicsthemed school field trip. This contrast is similar to the situation in the U.S., where the potentials of mathematics learning in informal settings have not received much attention (Anderson, 2001). A possible reason for this is a general lack of out-of-school learning opportunities for mathematics compared to those for science, since most science museum exhibits and science fairs in Korea are focused on hands-on science activities, whereas links to mathematics are fairly limited and implicit.

Another interesting contrast was found in Strand S. In Korea, STEM/STEAM education has been actively promoted by the government and integrated into the national curriculum for the past decade. A great deal of research has been supported with a significant amount of national funding, particularly on teacher professional development and STEAM curricular program development (Kang, 2019). Kang (2019) showed that $55 \%$ of elementary schools, $48 \%$ of middle schools, and $32 \%$ of high schools nationwide offered STEAM lessons regularly. Our analysis revealed that studies on these interdisciplinary approaches to teaching were more dominant in SER (6.9\%) than in MER (2.8\%). In both SER and MER, most of the studies on STEM/STEAM focused on developing, implementing, and testing the effect of STEM/STEAM education programs in diverse disciplinary and real-life contexts. As was the case in informal and out-of-school education, STEM/STEAM education research papers in SER outnumbered those in MER by more than twice. Despite the difference in volume, the research content within Strand $S$ was diverse in both fields, and no particular points of contrast were identified. These research topics ranged from theoretical studies on the integration of STEAM to the 


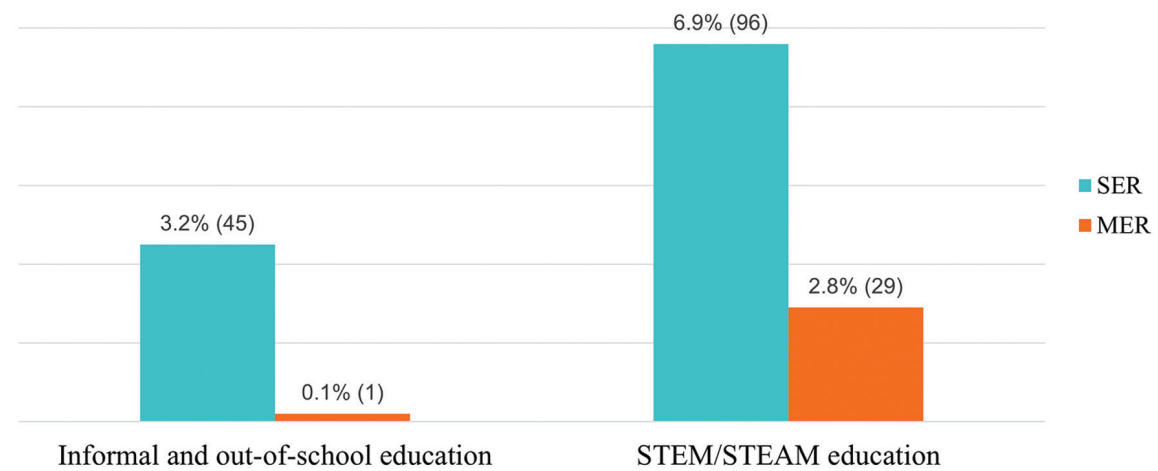

Informal and out-of-school education

STEM/STEAM education

FIGURE 5 Distribution of SER and MER articles on informal and out-of-school education and STEM/STEAM education

practical implementation of STEAM programs to students and evaluation of these programs.

\subsection{Other Research Topics}

The other four strands (Strands M, N, D, and G) were represented in SER and MER in similar proportions. Strand M, which includes meta-analyses of research methods and approaches and proposals of new methods, appeared at a similar frequency $(0.4 \%)$ in both fields. Also interesting was Strand N, which involved historical, philosophical, and social issues related to each discipline and using these issues in teaching science and mathematics. The results showed that the portions of this strand researched in both fields were simi$\operatorname{lar}(3.3 \%$ in SER and $3.9 \%$ in MER). In SER, studies on the nature of science (NOS) consistently appeared throughout the 5 years. With Nos having been a major subfield of SER at least during the past two decades, most SER studies in this strand were empirical, using data from questionnaires, interviews, textbooks, and so on to investigate teachers' and students' ideas about Nos and social issues in science. In contrast, almost all MER articles in this strand were theoretical or philosophical reflections on specific topics in the mathematics curriculum (e.g., communicative property of multiplication, trigonometric function, and sampling) or mathematics education in general (e.g., values, creativity, and epistemology in mathematics). Research on diversity and equity in SER and MER (Strand D) was relatively more differentiated. As shown in Figure 6, science education researchers published fewer articles about equity and diversity issues $(1.5 \%)$ than mathematics education researchers $\operatorname{did}(2.4 \%)$. 


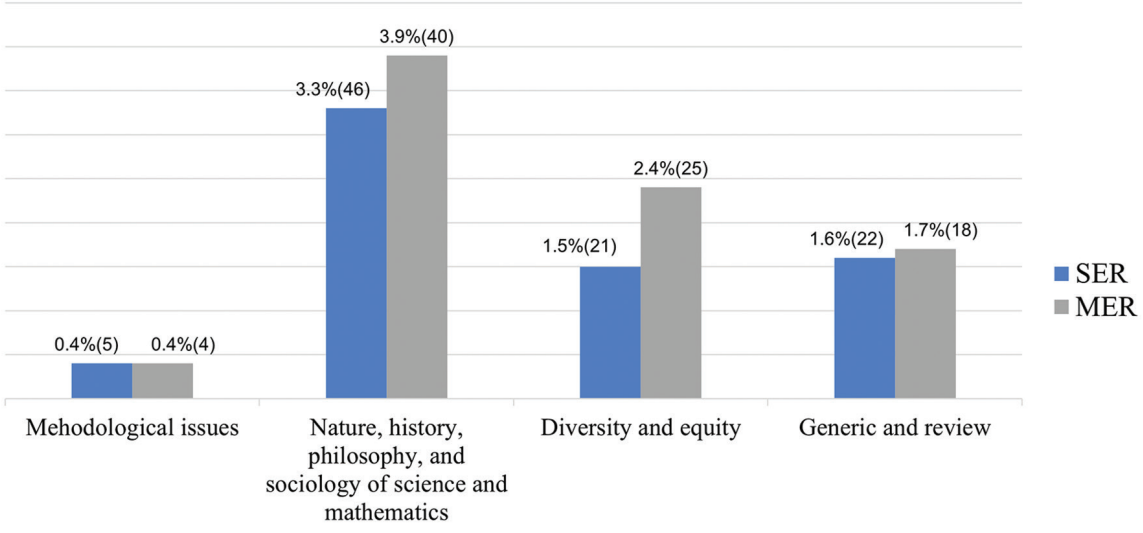

FIGURE 6 Distribution of SER and MER articles on methodological issues; nature, History, philosophy, and sociology of science and mathematics; diversity and equity; and generic and review

Strand G about review and meta-analysis of research literature was nearly proportionally equal in SER and MER ( $1.6 \%$ and $1.7 \%$, respectively).

\section{5}

\section{Discussion}

While science education and mathematics education are typically considered to be closely related disciplines, they have existed largely as separate research areas. The recent call for cross-subject collaboration to address complex issues in society and promote students' problem-solving skills (Drake \& Burns, 2004) has suggested the possibility for productive exchanges between the two fields. By shedding light on the trends in published research in SER and MER in Korea, this article provides initial information about the comparisons and contrasts between the two fields. Although the results are drawn from Korean journals, and thus generalizations should be made with caution, the comparison provides valuable information for considering the relationship between SER and MER, particularly with the mounting global interest in interdisciplinarity in education (Broggy, O'Reilly, \& Erduran, 2017) and collaboration between science and mathematics teachers (Wong \& Dillon, 2020). Below we discuss some implications and suggestions based on the findings.

In general, our comparative analysis showed that SER and MER in Korea have much in common in terms of their research topics. The distribution of research topics was similar enough to conclude that strands such as curriculum, 
policy, and assessment; learning and instruction; and teaching and teacher education are perceived as important enough to both science education and mathematics education researchers to take up the majority of publications in the two fields. This means that much of what constitutes the nature of the discipline, despite differences in fine-grained scale, is largely shared between science education and mathematics education researchers in Korea. It provides evidence that, as neighboring disciplines, science education and mathematics education researchers tend to pose similar types of research questions about what they are interested in. The precise reasons for these overarching similarities will need further investigation. Investigations into the sources of similarities and differences between the two fields by researcher surveys and interviews will provide further nuances to the findings reported in this study. A longitudinal analysis across a longer time frame would allow understanding how the research trends in each discipline have evolved over time, particularly when compared with the changes in national curriculum policy. Comparing the results to similar studies in other countries or on an international scale will be necessary to better understand the meanings of our findings from the Korean context. Also, determining whether these trends are specific to science and mathematics or generally valid for all branches of subject-based educational research will require an investigation of other school subjects such as language, humanities, and social studies.

The results also indicate that the existence of journals dedicated to specific subareas of SER or MER can make a significant shift in the landscape of research within a domain. For example, the existence of $s s J$ in SER resulted in a significantly greater number of articles on curriculum resources and textbooks (C2), because a major portion of articles in $s s J$ consist of research with practitioner-developed resources and methods for science teaching. Given the impact of the academic publishing system on shaping knowledge production and deciding what kind of research is valued among researchers (Goel \& Faria, 2007), it would be interesting to further explore the role of local journals in driving educational research, particularly in countries where English is not an official language.

In addition, we suggest that there is a range of opportunities for crosspollination between SER and MER as neighboring disciplines. The first potential collaboration opportunity involves the research areas in which either discipline is more active in research than the other. In this case, well-developed theoretical and methodological ideas can easily be adapted to the other discipline and elicit research because SER and MER share many common interests, as revealed in our research trend analysis. For example, science education 
researchers may consider looking at teachers' practices based on the theoretical ideas commonly employed by mathematics education researchers, such as didactic transposition theory (Chevallard, 1989), to gain new insights for their own research on professional development and teacher practice. Similarly, mathematics education researchers could benefit from theories related to informal science education research to enrich mathematics teaching outside classrooms. Second, science education and mathematics education researchers can engage more actively in the areas where their interests intersect, such as STEM/STEAM education. Since in-depth research on STEM/STEAM education would require knowledge and experience in both subjects, it would be essential to promote collaborations between science education and mathematics education researchers, which in turn can also lead to collaboration between practitioners. Likewise, further reflections on how argumentation research in SER and proof research in MER relate can provide insights on potential synergies. MER's focus on the formal logic of the mathematical proof and SER's focus on the social and communicative aspects of reasoning show that they have the potential to complement each other. Theories in multidisciplinarity, interdisciplinarity, and transdisciplinarity (Broggy, O'Reilly, \& Erduran, 2017; Klein, 2017) will be useful in exploring various potential modes of integration between SER and MER. The fact that STEM/STEAM research in SER and MER in Korea has a great deal of convergence in terms of research questions indicates that such collaborations would be quite plausible and promising. Given the recent focus on integrated STEM/STEAM research in the educational policy of Korea (Kang, 2019) and other countries (Anderson \& Li, 202O), the potential areas of integration and collaboration identified in this study will be helpful in deciding the priorities in terms of curriculum development, teacher training, and research funding. For example, investigating how science teachers' views of and approaches to STEAM compare with those of mathematics teachers will be useful for supporting science teachers to collaborate with mathematics teachers for STEAM integration. Likewise, the underrepresentation of diversity and equity issues in SER relative to MER is also worthy of note. The reasons for such difference were not apparent from this study and thus will need further investigation. For SER researchers, communicating with MER researchers may provide opportunities to promote these agendas within SER. For example, looking into the gender achievement gaps in science and mathematics through a comparative lens would be an important avenue for SER-MER collaboration. Theories and methods of informal science learning can inform mathematics learning in informal settings, which will be another interesting agenda for collaboration. 
Examples of exchanges between SER and MER outside of Korea offer further insights for facilitating cross-field fertilization both locally and globally. For example, it has been noted that the scarcity of SER on noticing has been rare not only in Korea but also elsewhere (Talanquer \& Bloger, 2015). In Russ and Luna's (2013) study, they built on the work on teacher noticing from mathematics education "to develop new approaches to modeling teacher cognition" (p. 284) in science education. They showed that this framework could be used to analyze one high school biology teacher's practices in the context of lab work and class discussions, showing how a theoretical concept from MER can be appropriated in SER. There are examples of cross-fertilization in the opposite direction. Wells (2014) is an example where argumentation research in science education informed a mathematics education project. Problematizing the focus of argumentation in MER on formal logic to "arrive at a correct answer" (p. 2), she attended to the power of argumentation in supporting ill-structured, ambiguous, and open-ended problems in mathematics. Taken together, these examples demonstrate the possibilities of SER and MER enriching each other through cross-field exchange.

Several limitations of this study should be noted. First, since the analysis was focused on article title, keywords, and (occasionally) abstract rather than the full text, it can provide limited information about comparisons on the micro-level, such as the trends in research methodology, the use of theory, and the specific contexts of empirical research. A more fine-grained analysis with a smaller volume of publications will be useful to investigate these issues. Second, our analysis did not consider how the trends changed over the 5 years, which will need further investigation. Given that SER and MER researchers are responsive to the changes in the national curriculum and other educational policies, a longitudinal analysis of research trends will provide insights for understanding how researchers respond to changes.

\section{Ethical Considerations}

The data reported in this study does not require human subjects' approval.

\section{About the Authors}

Wonyong Park is a Lecturer in Science Education in the Southampton Education School, University of Southampton. He received a doctorate in science education at the University of Oxford in 2021 and was a Science Tutor 
for the Master's in Learning and Teaching (MLT) programme there. Prior to his doctoral studies, he received BSc and MSc degrees in Physics education from Seoul National University, where he also trained as a physics teacher. His research focuses on the intersections of science, humanities and society in the context of education. He has published articles examining how history and philosophy of science can enrich science teaching in schools, which led to his interest in teaching the nature of science in science education. In recent years, he is also passionate about exploring the role of science and STEM education in building disaster-resilient society in the age of various local and global crises. In so doing, he is committed to interdisciplinary approaches between science and other subjects such as history, social studies, religious education and language and literature.

Doy Kim is a doctoral student in the Learning Sciences area of the Educational Psychology department at the University of Wisconsin. Doy is currently working with Dr. Mitchell Nathan, studying the impact of directed action and gestures on geometric reasoning. Before joining UW-Madison in 2019, he received his B.Sc. and M.Sc. in Mathematics Education from Seoul National University in South Korea. Professionally, Doy worked as a researcher for the Korea Educational Broadcasting System (EBS) developing online mathematics lectures for middle school students. He also worked as the manager of the training department at Center for In-service Teacher Education, developing curriculum and organizing training programs. During his M.Sc, he was a research assistant for a Social Sciences Korea funded project, Glocal Changes and Educational Response, where he studied the relationship between students' gestures and understanding of rational numbers in a digital learning environment from an embodied cognition perspective.

Da Yeon Kang is a doctoral candidate in Earth Science Education at Seoul National University. Her research focuses on expanding science teaching and learning opportunities in diverse contexts. She is particularly interested in improving teacher education programs, which expand teachers' exposure to and awareness of diverse learners in Korean K-12 science classrooms. She is also interested in engaging students in science activities to change their own lives and communities regarding socio-scientific issues. Her doctoral project specifically aims to understand the competences for taking socio-scientific action that youth activists enact concerning climate change and identify the social discourse that Korean society perceives youth climate actions. Currently, she is expanding her research scope to informal education contexts including developing science education programs at science museums. 


\section{References}

American Association for the Advancement of Science. (AAAS) (1989). Science for all Americans. Washington, DC: AAAs.

American Mathematical Society. (AMS). (2010). 2010 Mathematics Subject Classification. Retrieved June 5, 2019, from https://mathscinet.ams.org/mathscinet/msc/ msc2010.html.

Anderson, A. V. (2001). Mathematics in science centers. Washington, DC: Association of Science Technology Centers, Inc.

Anderson, J., \& Li, Y. (Eds.) (2020). Integrated approaches to STEM education: An international perspective. Dordrecht: Springer.

Bishop, A. (2008). Values in mathematics and science education: Similarities and differences. The Mathematics Enthusiast, 5(1), 47-58.

Broggy, J., O'Reilly, J., \& Erduran, S. (2017). Interdisciplinarity and science education. In K. Taber \& B. Akpan (Eds.), Science education: An international course companion (pp. 81-9o). Dordrecht: Springer.

Chevallard, Y. (1989, August). On didactic transposition theory: Some introductory notes. In Proceedings of the international symposium on selected domains of research and development in mathematics education (pp. 51-62). Bratislava, Czechoslovakia: Comenius University.

Chung, S.-I., \& Shin, D.-H. (2016). Trends of assessment research in science education. Journal of the Korean Association for Science Education, 36(4), 563-579.

Dolan, E. L., Elliott, S. L., Henderson, C., Curran-Everett, D., St. John, K., \& Ortiz, P. A. (2018). Evaluating discipline-based education research for promotion and tenure. Innovative Higher Education, 43(1), 31-39.

Drake, S. M., \& Burns, R. C. (2004). Meeting standards through integrated curriculum. Alexandria, VA: Association for Supervision and Curriculum Development.

English, L. D. (2016). STEM education K-12: Perspectives on integration. International Journal of STEM Education, 3(1), 3.

Erduran, S., \& Dagher, Z. R. (2014). Reconceptualizing the nature of science for science education. Dordrecht: Springer.

Ernest, P. (1997). A postmodern perspective on research in mathematics education. In A. Sierpinska \& J. Kilpatrick (Eds.), Mathematics education as a research domain: A search for identity (pp. 71-86). New York, NY: Springer.

European Science Education Research Association. (ESERA) (2019). Research strands. Retrieved 5/6/2019 from https://www.esera2019.org/reviewers/.

Fensham, P. (2003). Defining an identity: The evolution of science education as a field of research. Dordrecht: Springer.

Goel, R. K., \& Faria, J. R. (2007). Proliferation of academic journals: effects on research quantity and quality. Metroeconomica, $58(4), 536-549$. 
Hacking, I. (1996). The disunities of the sciences. In P. Galison \& D. J. Stump (Eds.), The disunity of science: Boundaries, contexts and power (pp. 37-74). Stanford, CA: Stanford University Press.

Jeon, S.-Y. (2013). A study on history of Korea science museum and promotion policy of science museum. Journal of Museum Studies, 24, 107-122.

Kang, N. H. (2019). A review of the effect of integrated STEM or STEAM (science, technology, engineering, arts, and mathematics) education in South Korea. Asia-Pacific Science Education, 5(1), Article 6.

Kim, J. Y. (2018). The citizen science stories in Korea: 1982-2018. Journal of Science \& Technology Studies, 18(2), 43-93.

Kim, Y., Paik, S.-H., Choi, S. Y., Kang, N.-H., Maeng, S., \& Joung, Y. J. (2015). Analysis on the trends of science education studies related to students' science learning in Korea. Journal of the Korean Association for Science Education, 35(4), 751-772.

Kim, Y., \& Pang, J. S. (2017). Research trends in elementary mathematics education: Focused on the papers published in domestic journals during the resent. Education of Primary School Mathematics, 2o(1), 19-36.

Klein, J. T. (2017). Typologies of Interdisciplinarity: The Boundary Work of Definition. In R. Frodeman (Ed.), The Oxford handbook of interdisciplinarity (pp. 21-34). Oxford: Oxford University Press.

Kuhn, T. S. (2012). The structure of scientific revolutions (4th ed.). Chicago, IL: University of Chicago Press.

Kwon, N., \& Ahn, J. (2012). The analysis on domestic research trends for convergence and integrated science education. Journal of the Korean Association for Science Education, 32(2), 265-278.

Kwon, S. K., Lee, M., \& Shin, D. (2017). Educational assessment in the Republic of Korea: Lights and shadows of high-stake exam-based education system. Assessment in Education: Principles, Policy and Practice, 24(1), 6o-77.

Lew, H. (2016). Developing and implementing "smart" mathematics textbooks in Korea. In M. Bates \& Z. Usiskin (Eds.), Digital curricula in school mathematics (pp. 35-51). Charlotte, NC: Information Age Publishing.

Lin, T.-C., Lin, T.-J., Potvin, P., \& Tsai, C.-C. (2018). Research trends in science education from 2013 to 2017: a systematic content analysis of publications in selected journals. International Journal of Science Education, $36(8)$, 1346-1372.

Lin, T.-C., Lin, T.-J., \& Tsai, C.-C. (2014). Research trends in science education from 2008 to 2012: A systematic content analysis of publications in selected journals. International Journal of Science Education, 36(8), 1346-1372.

Liu, W. (2017). The changing role of non-English papers in scholarly communication: Evidence from Web of Science's three journal citation indexes. Learned Publishing, $30(2), 115^{-123}$. 
Maeng, S., Seong, Y., \& Jang, S. (2013). Present states, methodological features, and an exemplar study of the research on learning progressions. Journal of the Korean Association for Science Education, 33(1), 161-180.

Morris, P., \& Marsh, C. (1992). Curriculum patterns and issues in East Asia: A comparative survey of seven East Asian societies. Journal of Education Policy, 7(3), 251-266.

National Association for Research in Science Teaching. (NARST) (2018). Strands. Retrieved 5/6/2019 from https://narst.org/strands.

OECD. (2018). PISA 2015: Results in focus. Paris: OECD.

OECD. (2019). PISA 2018 results: Combined executive summaries. Paris: OECD.

Park, S. Y., \& Kim, W. K. (2011). A comparative analysis on research trends of secondary mathematics education between Korea and overseas. The Mathematical Education, $50(3), 289-310$.

Park, W., \& Song, J. (2019). Between realism and constructivism: A sketch of pluralism for science education. In E. Herring, K. M. Jones, K. S. Kiprijanov \& L. Sellers, (Eds.), The past, present, and future of integrated history and philosophy of science (pp. 228-247). London: Routledge.

Park, W., Wu, J.-Y., \& Erduran, S. (2020). Investigating the epistemic nature of STEM: Analysis of curriculum documents from the USA using the Family Resemblance Approach. In Anderson, J., \& Li, Y. (Eds.) Integrated approaches to STEM education: An international perspective (pp. 137-155). Dordrecht: Springer.

Riesch, H., \& Potter, C. (2014). Citizen science as seen by scientists: Methodological, epistemological and ethical dimensions. Public Understanding of Science, 23(1), 107-120.

Russ, R. S., \& Luna, M. J. (2013). Inferring teacher epistemological framing from local patterns in teacher noticing. Journal of Research in Science Teaching, 50(3), 284-314.

Seth, M. J. (2002). Education fever: Society, politics, and the pursuit of schooling in South Korea. Honolulu, HI: University of Hawaii Press.

Shin, J., \& Choi, A. (2014). Trends in research studies on scientific argumentation and writing in Korea. Journal of the Korean Association for Science Education, 34(2), 107-122.

Sierpinska, A., \& Kilpatrick, J. (Eds.) (1997). Mathematics education as a research domain: A search for identity, (Book 2). Dordrecht: Springer.

Singer, S. R., Nielsen, N. R., \& Schweingruber, H. A. (2012). Discipline-based education research: Understanding and improving learning in undergraduate science and engineering. Washington, DC: National Academy Press.

Song, J. (2013). The disparity between achievement and engagement in students' science learning: A case of East-Asian regions. In D. Corrigan, R. Gunstone, \& A. Jones (Eds.), Valuing assessment in science education: Pedagogy, curriculum, policy (pp. 285-3o6). Springer Netherlands. 
Song, J., Ogawa, M., Wen, M. L., Mu, X., \& Na, J. (2016). Current trends of science education in East Asia (1995-2004): With a focus on local academic associations, journal papers, and key issues of science education in China Mainland, Japan, Korea, and Taiwan. In H. Lin, J. K. Gilbert, \& C.-J. Lien (Eds.), Science education research and practice in East Asia: Trends and perspectives (pp. 131-19o). Taipei: Higher Education Publishing.

Talanquer, V., Bolger, M., \& Tomanek, D. (2015). Exploring prospective teachers' assessment practices: Noticing and interpreting student understanding in the assessment of written work. Journal of Research in Science Teaching, 52(5), 585-6o9.

TIMSS and PIRLS International Study Center. (2015a). TIMSS 2015 International Reports - Mathematics. Retrieved 10 December 2019 at http://timssandpirls.bc.edu/ timss2015/international-results/timss-2015/mathematics/student-achievement/.

TIMSS and PIRLS International Study Center. (2015b). TIMSS 2015 International Reports - Science. Retrieved 10 December 2019 at http://timssandpirls.bc.edu/ timss2015/international-results/timss-2015/science/student-achievement/.

Tobin, K., \& Fraser, B. J. (1988). Investigations of exemplary practice in high school science and mathematics. Australian Journal of Education, 32(1), 75-94.

Wells, J. (2014). Developing argumentation in mathematics: The role of evidence and context. Queensland: The University of Queensland. (Unpublished doctoral thesis).

Wong, V., \& Dillon, J. (2020). Crossing the boundaries: collaborations between mathematics and science departments in English secondary (high) schools. Research in Science and Technological Education, 38(4), 396-416.

ZDM - Mathematics Education (ZDM). (n.d.). ZDM Subject Classification Scheme. Retrieved 5 June 2019 from http://www.imvibl.org/dmbl/novosti/zdm_didactical _mathematics_mlassification.pdf. 